vol.5, Special Issue - 2018

\title{
MATERNAL SEMI SITTING VERSUS LITHOTOMY POSITION DURING SECOND STAGE OF LABOR ON MATERNAL OUTCOMES
}

Nehmedo Ezzat ${ }^{1 *}$, Hanan Nabil ${ }^{2}$, Tyseer Marzouk ${ }^{1}$, Amina El-Nemer ${ }^{1}$

1 Woman's Health and Midwifery Department, Faculty of Nursing-Mansoura University, Egypt 2 Obstetrics and Gynecology Department, Faculty of Medicine-Mansoura University, Egypt

Abstract

E-mail om.sama84@yahoo.com

\begin{abstract}
Aim of this study was to compare the effect of maternal semi sitting versus lithotomy position during second stage of labor on maternal outcomes. Subjects and method: A quasi-experimental study was conducted at the Labor and Delivery Room of Mansoura University Hospital, on a purposive sample of 96 parturient women in active labor; 48 assigned to study group by assuming the semi sitting position during second stage of labor, while the control group $(n=48)$ adopted the conventional lithotomy position. Data were collected using three tools; a structured interview questionnaire, Visual Analogue Scale for pain and satisfaction with the assumed position scale. Results: The intervention group had more efficient contractions, shorter $2^{\text {nd }}$ stage duration, less perineal lacerations, lower labor pain scores and higher satisfaction scores compared to those of the control group. Conclusion and recommendations: Positioning of parturient women in semi sitting position had a positive impact on maternal outcomes and woman's satisfaction with the care provided. Accordingly, semi sitting position would be an integral part of the nursing care during second stage of labor.
\end{abstract}

Keywords: labor, second stage, lithotomy position, semi sitting position

\section{Introduction:}

Labor and birth process are an exciting, painful and anxiety provoking situation for women (1). In a relatively short period; particularly in second stage of labor, the woman experiences some of the most painful experience in her live (2). Studies have shown that selecting maternal position during second stage of labor is important, because descent of the fetal head and maternal bearing down efforts are enhanced by one position rather than another ${ }^{(3)}$.

Physiologically, the supine lithotomy position has been observed to be associated with compression of major abdominal vessels, weaker uterine contractions, poor bearing down efforts, increased instrumental deliveries, increased labor pain, prolonged duration of labor, irregular fetal heart rate patterns and intrauterine hypoxia ${ }^{(4)}$.
Conversely, upright positions; like sitting, kneeling, hands-and-knees/all-fours, squatting and standing; have multi advantages, where it lead to opening the pelvic outlet as widely as possible; improving fetal position and aiding rapid fetal descend, enables force of gravity to help the baby move down; giving the mother a sense of being safe and in control of the process; and most importantly, decreasing maternal-neonatal risk of injury ${ }^{(5)}$.

Effective maternity care with least harm is seeked for childbearing women and newborns ${ }^{(6)}$. However, practices that are appropriate for mothers and babies in limited circumstances are in wide use, and advantageous practices are underused. Some variables influence the actual practices, as health provider preference and training, birthing equipment 
availability, analgesia choice, fetal monitoring method and conventional policy in labor ${ }^{(7)}$.These gaps between actual practice and lessons of best evidence reveal tremendous opportunities to improve the outcomes of maternity care for women and babies ${ }^{(8)}$.

\section{Significance of the study}

Evidence based care practices; facilitating physiological birth by avoiding needless induction of labor, encouraging use of alternative birth positions, providing continuous labor support, avoiding routine intervention and restriction, encouraging spontaneous pushing in non-supine positions, and keeping mothers and babies together after birth without restriction on breastfeeding (9). Evidence has been found that uses of the alternative position as semi sitting position during second stage of labor positively affect maternal and neonatal outcomes. Maternal outcomes are increasing the uterine contraction and increasing women's satisfaction. Also, decreasing the duration of the second stage, the level of pain, episiotomy, and the rate of cesarean birth ${ }^{(8 ; 4)}$.Using supine position in labor in Mansoura labor ward. Women are not satisfied with the quality and routine care provided in labor ward. Consequently the CS rate in Egypt was nearly doubled from $28 \%$ in 2008 to $52 \%$ in 2014, and increased greatly in Dakahlia Governorate to reach $65.5 \%$ in $2014^{(10)}$. Thus, the current study aims to apply semi sitting versus lithotomy position during second stage of labor on maternal and neonatal outcomes.

\section{Aim of the study}

The present study aims to study maternal semi sitting versus lithotomy position during second stage of labor on maternal outcomes.

\section{Study hypothesis}

To achieve the present study aim, one hypothesis was tested "Parturient women who adopt the semi-sitting position during second stage of labor will experience better maternal outcomes compared to those who adopt the lithotomy position."

\section{Research Design}

A quasi-experimental research design was followed to study maternal semi sitting versus lithotomy position during second stage of labor.

\section{Study setting}

This study was carried out at the Labor and Delivery Room of Mansoura University Hospital. It is located at the first floor of the main hospital's building; within the main unit of Labor and Delivery. It contains 2 delivery tables and enclosed small unit for immediate baby care with a warmer device and suction machine.

\section{Subjects}

All parturient women attended the Labor and Delivery Room in active labor; between July 2016 to June 2017, were eligible to be enrolled in this research after fulfilling the following inclusion criteria:

- Have a singleton, term, viable fetus in vertex presentation.

- Free from any Obstetrical and medical complications.

- Expected to spontaneously deliver vaginally.

\section{Sample size calculation}

A purposive sample of 96 women was recruited significant difference of pain reduction between two groups; elevated back position of $60^{\circ}$ and routine lithotomy position group, using a two-tailed z-test of proportions with $80 \%$ power and 5\% level of significance. Sample size was calculated by substitution of the following formula:

$n=[2(Z \alpha / 2+Z \beta) 2 \times p 1(1-p 1)] /(p 1-p 2) 2$

where, $\mathrm{n}=$ sample size required in each group, $\mathrm{p}=$ pooled proportion (proportion of event in group $1+$ proportion of event in group 2)/2, and p1p2 = difference in proportion of events in two groups. $Z \alpha / 2$ depends on level of significance, for $5 \%$ this is 1.96 , and $Z \beta$ depends on power, for $80 \%$ this is 0.84 . 
MATERNAL SEMI SITTING VERSUS LITHOTOMY etc ...

Thus, $\mathrm{n}=48$ per each group. Therefore, a total sample of 96 parturient women was selected by fitting the previously mentioned inclusion criteria. The firstly met parturient women $(n=48)$ were allocated to the control group, while the secondly attended parturient women $(n=48)$ were allocated to the intervention group.

1. Intervention group $(n=48)$ : was assumed the semi sitting position during second stage of labor; where the woman's back was elevated to a 60 angle by applying a simple backrest attached to the adjustable delivery table.

2. Control group $(n=48)$ : was adopted the conventional lithotomy position during second stage of labor. This position involves positioning of a woman's feet above or at the same level as the hips; often in stirrups, with the perineum positioned at the edge of an examination table.

\section{Data Collection Tools}

Data was collected by using three tools; specifically, structured questionnaire, visual analogue scale for pain, and maternal satisfaction scale with the assumed position.

\section{Tool I: Structured Questionnaire}

It was designed by the researcher based on reviewing the scientific literature, and consists of three parts:

Part 1. Entails the participants' demographic data such as age, level of education, residence, height, weight, body mass index,.....etc.

Part 2. Concerns with the obstetric profile (e.g., gravidity, parity, number of abortions), and the current delivery data (e.g., parturient vital signs, gestational age, state of membranes, duration of first stage of labor).

Part 3. Entails the maternal outcomes; such as nature of uterine contractions, molding, fetal heart rate, duration of second stage, mode of delivery, perineal state.
Tool II: Visual Analogue Scale for pain (VAS-pain)

This scale was developed by 11) to measure intensity of the labor pain. It is a horizontal line marked in millimeters from 0 to 100 with two opposing extremes at each end; where 0 indicates no pain and 100 represents the worst possible pain. Labor pain score was determined by measuring the distance from 0 to the marked pain location.

Tool III: Maternal satisfaction with assumed position

Maternal satisfaction was assessed by asking the participants: "Are you satisfied with your assumed position during second stage of labor?". Participants responses were assessed using a five point Likert scale; where strongly disagree scored 1, disagree scored 2, undecided scored 3, agree scored 4, while strongly agree scored 5. Total score ranged from 1 to 5, the higher score indicates the higher satisfaction.

\section{Ethical considerations}

Official permissions were taken from the Ethics Committee of the Faculty of Nursing, Mansoura University, as well from the concerned authorities in Mansoura University Hospital before conducting the present study. Prior to the study, written consent was obtained from each parturient woman after clarification of the study nature. During the research process, no harmful maneuvers were performed and no predicted hazards were awaited from leading the study on parturient women.

\section{Research process}

The process was conducted through three phases; preparation for the intervention, implementation of the intervention, and evaluation of the outcomes.

Preparation phase

The study tools were prepared by the researcher after reviewing the related literature and were checked for its validity 
and reliability and recommended modifications were done. Piloting was conducted on $10 \%$ of the total sample; 10 eligible women, to test the feasibility of the study and to estimate the time needed for data collection. The pilot study revealed that the statements of the tools were clear; thus no modifications were done and the pilot sample was included to the total sample.

\section{Implementation phase}

Upon obtaining official approvals for conducting this study, the intervention was clarified to the Labor and Delivery Room staff; to gain their cooperation during the data collection process, actual fieldwork was started in July 2016. Parturient women were enrolled in this study by signing written consent form. The researcher attended the study setting three days weekly for six hours daily. Each eligible woman was asked to complete the structured questionnaire form. Then, each one was subjected to complete physical assessment upon admission. Thereafter, received the assigned intervention; either assuming semi-sitting position or lithotomy position during second stage of labor; according to their attendance time, where the first attended 48 eligible women were assigned to the control group, while the second attended 48 eligible women were assigned to the intervention group.

\section{The intervention group}

These groups were asked to assume the upright semi sitting position during the second stage of labor. This position was characterized by that the woman with her body weight on her buttocks and her torso inclined 60 degrees behind from the upright axis (8). It was achieved by elevating the woman's back to 60 angles using the backrest attached adjustable delivery table.

\section{The control group}

Participants of this group were subjected to take the conventional lithotomy supine position during second stage of labor. This position involves positioning of a woman's feet above or at the same level as the hips; often in stirrups, with the perineum positioned at the edge of an examination table.

\section{Outcome evaluation phase}

Certain maternal outcomes were assessed in this study; specifically, duration of the second and third stages of labor, occurrence of perineal tears, need for episiotomy incision, maternal postpartum blood loss $\geq 500 \mathrm{ml}$, labor pain intensity, and maternal satisfaction with the assumed position.

Using a stop watch, duration of the second and third stages of labor were identified; where the second stage of labor was started by full cervical dilation until baby expulsion, while the third stage was started by childbirth and ended by placental expulsion. Perineal tears were classified according to the following definitions (12). An intact perineum was defined as absence of tissue separation at any site. First-degree tear; defined as the laceration is restricted to the fourchette and superficial perineal skin or vaginal mucosa, second-degree tear; indicated that the laceration extends outside fourchette, perineal skin and vaginal mucosa to perineal muscles, but not involved the anal sphincter, while the third-degree tear; refers to that the laceration is further extended to the anal sphincter.

Amount of blood loss during the third stage of labor was determined by collecting such blood in a clean metal receptacle that was kept at the tail end of the delivery table and then it was poured in a plastic graduated jar to determine its amount in milliliters. After about two hours; where the postpartum woman got some rest after childbirth, the woman was asked to rate the labor pain and satisfaction with the assumed position during the second stage of labor by 
responding to the VAS-Pain scale and the two items-questionnaire.

\section{Statistical design}

Data were collected, then entered, processed, and analyzed using IBM-SPSS software (version 21.0).Qualitative data, e.g., sex were expressed as count \& percent. Quantitative data e.g., age were initially tested for normality using ShapiroWilk test and data were considered as normally distributed if $\mathrm{p}$ value $>0.050$. Quantitative data were expressed as Mean \pm SD if normally distributed or Median and Inter-quartile range if not normally distributed. Qualitative data were compared using Chi- square or Fisher's exact test when appropriate. Quantitative data were compared between two groups using Independent-Samples t-test if data are normally distributed or the nonparametric Mann-Whitney-U test if not. The result was considered as significant if $\mathrm{p}$ value $\leq 0.050$.

\section{Results}

Table 1 shows distribution of the intervention and control groups according to demographic data. It clarifies that both groups were identical; $p$ value $>0.05$, for maternal age, parity number, history of abortion, previous Cesarean Section, and gestational age.

Table 2 shows that most of the control group $(93.8 \%)$, had infrequent uterine contractions (1-2/10 min), while $52.1 \%$ of the intervention group showed frequent uterine contractions (3-4/10 $\mathrm{min}$ ). Uterine contractions persisted for more than $50 \mathrm{sec}$ in $87.5 \%$ of the intervention group and persisted for less than $40 \mathrm{sec}$ in $52.1 \%$ of the control group. Uterine contractions were strong in almost all of the intervention group (98.6\%), compared to $37.5 \%$ of the control group. Differences observed between the intervention and control groups were statistically significant uterine contractions frequency, duration, and intensity $(\mathrm{p}=<0.0001)$.
Table 3 indicates that the placenta was delivered spontaneously in all of the intervention group, while $8.3 \%$ of the control group required manual removal for the placenta. It also, shows that most of the intervention and control groups $(97.9 \%$ \& $93.8 \%$ respectively) lost average amount of blood during $3^{\text {rd }}$ stage of labor $(<500$ $\mathrm{ml})$. Differences observed were not statistically significant for mode of placenta delivery and the estimated amount of blood loss (p 0.117 \& 0.617 respectively). Additionally, participants of the intervention group consumed shorter time to expel their fetuses compared to the control group (8-35 vs. 15-45 minutes respectively; $\mathrm{P}<0.001)$ (Figure 1).

Table 4 shows that half of the intervention kept their perineum intact, compared to $39.6 \%$ of the control group. One quarter of the intervention group compared to $72.9 \%$ of the control group, were subjected for episiotomy incisions. Perineal edema affected $27.1 \%$ of the control group; however $8.3 \%$ only in the intervention group was exposed to perineal edema. Differences observed for the three items; intact perineal state, episiotomy, and perineal edema, were statistically significant ( $\mathrm{p}$ values were $0.031,<0.001$, $\& 0.016$ respectively). But differences were not statistically significant for the degree of perineal tears.

Table 5 signifies that half of the intervention group experienced moderate pain level, while $62.5 \%$ of the control group expressed severe pain level. Worst labor pain affected $29.2 \%$ of the control group compared to $4.2 \%$ of the intervention group. There was high statistically significant difference regards intensity of labor pain between the two study groups ( $\mathrm{P}<0.0001 \& \mathrm{X}^{2} 25.87$ ).

Figure 2 displays that $85.4 \%$ of the intervention group, was satisfied by adopting the semi sitting position, while $58.3 \%$ of the control group was not satisfied by adopting the lithotomy 
Nehmedo Ezzat et. al.

position during the second stage of labor.

A highly statistically significant difference was observed between the two

Table 1: General characteristics of the interven

\begin{tabular}{|c|c|c|c|c|c|c|}
\hline \multirow[t]{2}{*}{ Variables } & \multicolumn{2}{|c|}{$\begin{array}{c}\text { Intervention } \\
\text { group } \\
(n=48)\end{array}$} & \multicolumn{2}{|c|}{$\begin{array}{c}\text { Control group } \\
\quad(n=48)\end{array}$} & \multicolumn{2}{|c|}{$\begin{array}{c}\text { Test of } \\
\text { significance }\end{array}$} \\
\hline & $\mathbf{n}$ & $\%$ & $\mathbf{N}$ & $\%$ & $\mathbf{X}^{2}$ & $\mathbf{P}$ \\
\hline \multicolumn{5}{|l|}{ Age } & \multirow{6}{*}{$\begin{array}{c}3.0 \\
2\end{array}$} & \multirow{6}{*}{0.221} \\
\hline Mean \pm SD & & 6.5 & & 6.2 & & \\
\hline \multicolumn{5}{|l|}{ Parity } & & \\
\hline 0 or 1 & 37 & 77.1 & 30 & 62.5 & & \\
\hline 2 or 3 & 11 & 22.9 & 17 & 35.4 & & \\
\hline$\geq 4$ & 0 & 0.00 & 1 & 2.1 & & \\
\hline \multicolumn{5}{|l|}{ History of abortion } & \multirow{3}{*}{$\begin{array}{c}2.1 \\
8\end{array}$} & \multirow{3}{*}{0.268} \\
\hline Yes & 2 & 4.2 & 6 & 12.5 & & \\
\hline No & 46 & 95.8 & 42 & 87.5 & & \\
\hline \multicolumn{5}{|c|}{ Previous Cesarean Section } & \multirow{3}{*}{$\begin{array}{c}2.0 \\
4\end{array}$} & \multirow{3}{*}{0.495} \\
\hline Yes & 0 & 0.00 & 2 & 4.2 & & \\
\hline No & 48 & 100 & 46 & 95.8 & & \\
\hline \multicolumn{5}{|l|}{ Gestational age } & \multirow{3}{*}{$\begin{array}{c}3.0 \\
1\end{array}$} & \multirow{3}{*}{0.083} \\
\hline $37-$ & 38 & 79.17 & 44 & 91.7 & & \\
\hline $40-41$ & 10 & 20.83 & 4 & 8.3 & & \\
\hline
\end{tabular}

Table 2. Characteristics of uterine contractions in the intervention and control groups during second stage of labor $(n=96)$

\begin{tabular}{|c|c|c|c|c|c|c|}
\hline \multirow[t]{2}{*}{ Characteristics } & \multicolumn{2}{|c|}{$\begin{array}{l}\text { Intervention } \\
\text { group }(n=48)\end{array}$} & \multicolumn{2}{|c|}{$\begin{array}{c}\text { Control group } \\
(n=48)\end{array}$} & \multicolumn{2}{|c|}{$\begin{array}{c}\text { Test of } \\
\text { significance }\end{array}$} \\
\hline & n & $\%$ & $\mathbf{N}$ & $\%$ & $\mathbf{X}^{2}$ & $\mathbf{P}$ \\
\hline \multicolumn{5}{|c|}{ Frequency of uterine contraction } & \multirow{3}{*}{24.4} & \multirow{3}{*}{$<0.001$} \\
\hline $1-2 / 10$ minutes & 23 & 47.9 & 45 & 93.8 & & \\
\hline 3-4 / 10 minutes & 25 & 52.1 & 3 & 6.2 & & \\
\hline \multicolumn{5}{|c|}{ Duration of uterine contraction } & \multirow{4}{*}{60.13} & \multirow{4}{*}{$<0.001$} \\
\hline$<40 \mathrm{sec}$ & 0 & 0.00 & 25 & 52.1 & & \\
\hline $40-50 \mathrm{sec}$ & 6 & 12.5 & 18 & 37.5 & & \\
\hline$>50 \mathrm{sec}$ & 42 & 87.5 & 5 & 10.5 & & \\
\hline \multicolumn{5}{|c|}{ Intensity of uterine contraction } & \multirow{4}{*}{29.65} & \multirow{4}{*}{$<0.001$} \\
\hline Mild & 2 & 4.2 & 3 & 6.3 & & \\
\hline Moderate & 3 & 6.3 & 27 & 56.3 & & \\
\hline Strong & 43 & 98.6 & 18 & 37.5 & & \\
\hline
\end{tabular}


MATERNAL SEMI SITTING VERSUS LITHOTOMY etc...

Table 3. Distribution of the intervention and control groups according to mode of placental delivery and amount of blood loss $(n=96)$

\begin{tabular}{|c|c|c|c|c|c|c|}
\hline & \multicolumn{2}{|c|}{$\begin{array}{c}\text { Intervention group } \\
(n=48)\end{array}$} & \multicolumn{2}{|c|}{$\begin{array}{c}\text { Control group } \\
(n=48)\end{array}$} & \multicolumn{2}{|c|}{$\begin{array}{c}\text { Test of } \\
\text { significance }\end{array}$} \\
\hline & $\mathbf{n}$ & $\%$ & $\mathbf{n}$ & $\%$ & $\mathbf{X}^{2}$ & $\mathbf{p}^{*}$ \\
\hline \multicolumn{7}{|l|}{ Mode of placenta delivery } \\
\hline Spontaneous delivery & 48 & 100 & 44 & 91.7 & & \multirow{2}{*}{0.117} \\
\hline Manual removal & 0 & 0.00 & 4 & 8.3 & & \\
\hline \multicolumn{7}{|c|}{ Estimated amount of blood } \\
\hline$<500 \mathrm{ml}$ & 47 & 97.9 & 45 & 93.8 & 1.04 & \multirow{2}{*}{0.617} \\
\hline$\geq 500 \mathrm{ml}$ & 1 & 2.1 & 3 & 6.3 & 3 & \\
\hline
\end{tabular}

P* = Fisher's Exact Test

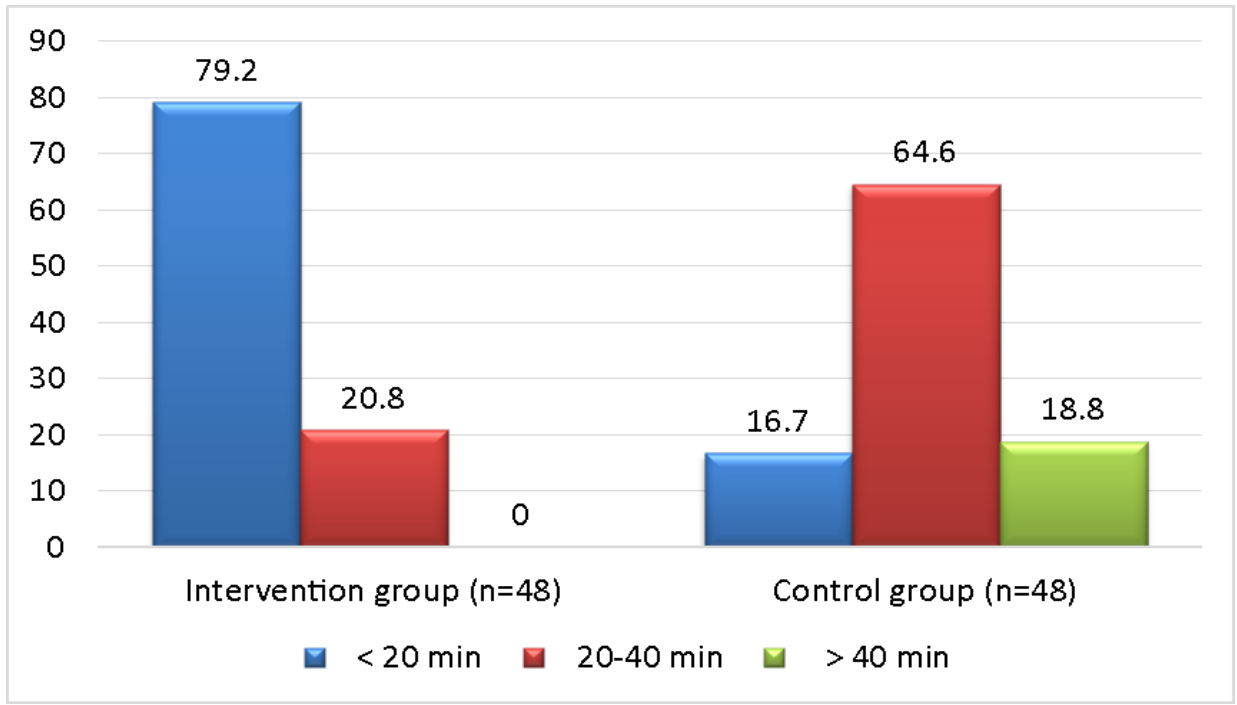

Figure 1. Duration of the second stage of labor in the intervention and control groups $(n=96)$ 
Nehmedo Ezzat et. al.

\begin{tabular}{|c|c|c|c|c|c|c|}
\hline \multirow[t]{2}{*}{ Perineal condition } & \multicolumn{2}{|c|}{$\begin{array}{l}\text { Intervention group } \\
(n=48)\end{array}$} & \multicolumn{2}{|c|}{$\begin{array}{l}\text { Control group } \\
\quad(n=48)\end{array}$} & \multicolumn{2}{|c|}{$\begin{array}{c}\text { Test of } \\
\text { significance }\end{array}$} \\
\hline & $\mathbf{n}$ & $\%$ & $\mathbf{N}$ & $\%$ & $\gamma^{2}$ & $\mathbf{P}$ \\
\hline Intact & 24 & 50 & 19 & 39.6 & 1.05 & 0.031 \\
\hline Minor laceration & 15 & 31.3 & 21 & 43.8 & 1.60 & 0.206 \\
\hline $1^{\text {st }}$ degree tear & 8 & 16.7 & 8 & 16.7 & 0 & 1 \\
\hline $2^{\text {nd }}$ degree tear & 1 & 2.1 & 0 & 0.0 & 1.01 & 0.315 \\
\hline Perineal edema & 4 & 8.3 & 17 & 27.1 & 5.79 & 0.016 \\
\hline $\begin{array}{l}\text { Episiotomy } \\
\text { incision }\end{array}$ & 12 & 25 & 35 & 72.9 & 22.05 & $<0.001$ \\
\hline
\end{tabular}

Numbers in this table are not exclusive

Table 5. Intensity of labor pain among the intervention and control groups $(n=96)$

\begin{tabular}{|c|c|c|c|c|c|c|}
\hline \multirow[t]{2}{*}{ Intensity of labor pain } & \multicolumn{2}{|c|}{$\begin{array}{c}\text { Intervention } \\
\text { group } \\
(\mathrm{n}=48)\end{array}$} & \multicolumn{2}{|c|}{$\begin{array}{l}\text { Control group } \\
\qquad(n=48)\end{array}$} & \multicolumn{2}{|c|}{$\begin{array}{c}\text { Test of } \\
\text { significance }\end{array}$} \\
\hline & $\mathbf{n}$ & $\%$ & $\mathbf{N}$ & $\%$ & $\mathbf{X}^{2}$ & $\mathbf{P}$ \\
\hline \multicolumn{5}{|l|}{ Intensity of labor pain } & \multirow{5}{*}{25.87} & \multirow{5}{*}{$\begin{array}{c}< \\
0.001\end{array}$} \\
\hline Mild & 1 & 2.1 & 0 & 0.0 & & \\
\hline Moderate & 24 & 50 & 4 & 8.3 & & \\
\hline Severe & 21 & 43.8 & 30 & 62.5 & & \\
\hline Worst & 2 & 4.2 & 14 & 29.2 & & \\
\hline
\end{tabular}

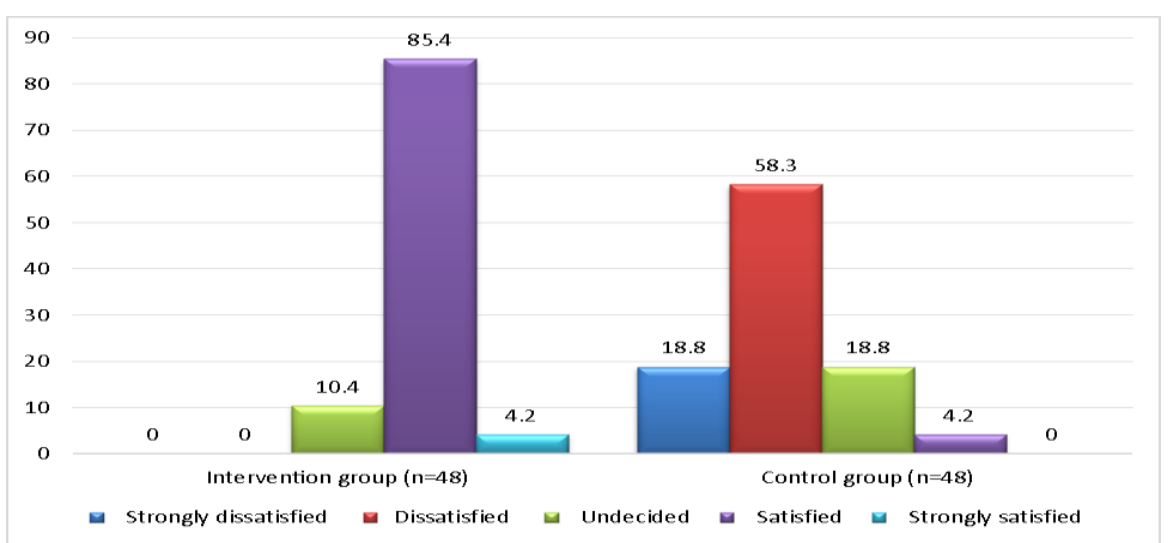

Figure 2. Mother's satisfaction by the position assumed during the $2^{\text {nd }}$ stage of labor among the intervention and control groups $(n=96)$.

\section{Discussion}

The present study aimed to study maternal semi sitting versus lithotomy position during second stage of labor. This aim was achieved through the present study findings which revealed beneficial maternal-neonatal outcomes of assuming semi-sitting compared to assuming lithotomy position. Maternal outcomes were investigated in relation to assuming one of the two studied positions for quality of uterine contractions, duration of second and third stage of labor, need for episiotomy incision and perineal tears, 
MATERNAL SEMI SITTING VERSUS LITHOTOMY etc ...

blood loss, intensity of labor pain, and maternal satisfaction with the assumed position.

Quality of uterine contractions was evaluated for its frequency per ten minutes, duration, and intensity. The present study findings revealed significant differences between the intervention and control groups in the frequency, duration, and intensity of uterine contractions during the second stage of labor. Parturient women of the intervention group had more frequent, longer, and stronger uterine contractions compared to the control group. This finding is consistent with the finding of a national quasi-experimental study, conducted on low risk parturient women at Beni-Suef Governorate, Egypt. Such study compared the effect of maternal semi-sitting or dorsal recumbent versus lithotomy position on maternal and neonatal outcomes (Mohamed et al ${ }^{(13)}$.

The current study demonstrated a highly statistically significant difference between the intervention and control groups regarding duration of second stage of labor. Participants of the intervention group consumed shorter time to deliver compared to the control group by a mean difference of 12.9 minutes.

The shorter duration of second stage of labor, that was reported in the present study may be explained by two rationales. Firstly, the semi-sitting position allows descent of the fetal head by effect of gravity which enhances expulsion of the fetus from the birth canal, and secondly the more efficient uterine contractions experienced by the intervention group stimulated rapid pushing of the fetus out of the birth canal; consequently shortened the $2^{\text {nd }}$ stage duration.

Authors of the present study assessed the perineal state in the participants of the two study groups. In terms of need for episiotomy, degree of perineal tears, or presence of perineal edema. Concerning need for episiotomy incisions, half the intervention group kept perineum area intact. Besides, episiotomy incision was indicated for higher percentage of the control group compared to the intervention group, with a statistically significant difference between the both groups. Significant differences were also observed for perineal edema in favor to the intervention group. But differences were not statistically significant for the degree of perineal tears.

This finding was agreed with that of Mohamed et al. (13). They reported that the semi-sitting position was more advantageous for obstetric injuries; where adopting semi-sitting resulted in lower episiotomy incisions, labial injury, perineal edema, and perineal lacerations compared to the lithotomy position. Although Thies-Lagergren et al (14), supported the mentioned conclusion, their finding revealed a lower episiotomy rate (1.9 to $11 \%$ compared to $25-72.9 \%$ in the current study). Henceforth, the episiotomy rate in the current study may be related to that the episiotomy as a one of many malpractices still performed irrespective individualized need is present or no; for Egyptian nulliparous women.

Conversely, Jakeman and Aimee (15), reported another finding according to a meta-analysis done on seven randomized controlled study to evaluate the integrity of the perineal muscle. Such meta-analysis concluded that assuming supine position during the second stage of labor is associated with decreased spontaneous perineal trauma compared to the nonsupine positions. Jakeman and Aimee ${ }^{(15)}$, attributed their finding; why the supine position may reduce perineal trauma, to two possible reasons: 1) the supine position reduces the pressure placed on the perineum, 2) the supine position increases the attending medical provider's access to the birth canal and perineum. Whereas, the authors of the present study explained the opposite finding by the reduced duration 
of the second stage of labor with its associated effect on rapid fetal expulsion and the decreased duration of pressure on the perineum.

Amount of the immediate blood loss was estimated in this study and the finding showed that most of the intervention and control groups, lost average amount of blood during 3rd stage of labor $(<500 \mathrm{ml})$, with no statistically significant difference. This finding was consistent with the finding of a randomized controlled study conducted by Bomfim-Hyppolito ${ }^{(16)}$, on 248 parturient women; 127 assumed the semi-sitting position while 121 assumed the supine position. Such study compared between the two groups in terms of blood loss and reported a non-significant difference between both groups. Additionally, Thilagavathy (17), reported a mean difference of $10 \mathrm{ml}$ blood loss higher in the semi-sitting group compared to the lithotomy group, but with no significant difference.

However, Gupta et al ${ }^{(18)}$ reported that assuming upright positions during the second stage of labor was a risk factor for losing blood volume more than $500 \mathrm{ml}$. Parallel, Mohamed et al (13), found the participants who assumed the semi-sitting position during second stage of labor were less likely to experience postpartum hemorrhage compared to the lithotomy position group. Such disagreement between the two opposite findings, may be explained by the difference in participants' culture, sample size, or method of assessment of the blood loss.

Using the 100 point VAS-pain scale, intensity of labor pain was assessed in the present study. A highly statistically significant difference was documented between the two study groups in favor to the intervention group. Nilsen et al (19), concluded that women who were adopted the semi-sitting position $(n=186)$, reported that the pain felt during second stage of labor was tolerable compared to those adopted the lithotomy position $(n=46)$. Thilagavathy (17), reported a significant decrease in labor pain intensity by a mean difference of $12 \mathrm{~mm}$ in the same pain assessment tool that was used in the present study, among the supported sitting group compared to the control group. Moreover, Valiani et al ${ }^{(20)}$, evaluated the intensity of labor pain by 100-ml VASpain scale among 96 primiparous pregnant women and reported a significant reduction of pain severity in the second labor stage in squatting position compared to lithotomy positions. Authors of the present study, attributed the significant reduction in labor pain intensity that was evidenced in the semi-sitting group to the belief that in this position there is no pressure against sacroiliac joints and the nerves that are responsible about pain transmission.

On the other hand, a randomized controlled trial was conducted in eleven hospitals in China on a total number of 1400 parturient women assigned randomly to experimental group; who delivered in hands-and-knees position or control group; who delivered in supine position. Such study aimed to investigate the effect of upright versus lithotomy positions on maternal-neonatal outcomes, and failed to find a significant reduction in pain level among the two positions groups

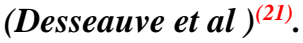

Even though, the lithotomy position was the common and best choose for the maternity staff, participants of the control group in this study reported lower satisfaction by the position assumed during $2^{\text {nd }}$ stage of labor compared to the intervention group. This finding is consistent with a number of studies equally documented higher satisfactions among the non-supine position compared to the supine position.

Mohamed et al ${ }^{(13)}$, demonstrated a higher satisfaction with the semi-sitting 
position compared to the lithotomy group. AlkaDani et al (22) reported a higher maternal satisfaction in non-supine position group compared to the supine one in a randomized controlled trial conducted at Mumbai, on a convenience sample of 200 parturient women. The present study authors gave a fairly reasonable for such finding, that is the feeling of satisfaction or dissatisfaction is surely related to the feelings of pain or discomfort and both were evidenced to be lower in the present study.

Conclusion and recommendations

According to the present study findings, adopting the semi-sitting position during the second stage of labor was a safe and better option for the maternal-neonatal welfare. Specifically, it was resulted in efficient uterine contractions, shorter second stage of labor, lower rate of perineal tears and episiotomy incisions, less exposure to out of accepted average of blood loss, lower labor pain intensity, higher satisfaction with and preference for this position.

\section{References}

1. Tuschy B, Berlit S, Stützer P, Lis S, Schmahl C, Baumgärtner $U$, Sütterlin M. Evaluation of psychosocial and biological parameters in women seeking for a caesarean section and women who are aiming for vaginal delivery: a cross-sectional study. Archives of gynecology and obstetrics. 2018 Jan 17:1-9.

2. Gaffka K. The Effect of Alternative Labor Positions Versus the Lithotomy Position on Birthing Outcomes: An Integrative Literature Review. 2016.

3. The American College of NurseMidwives. Evidence-Based Practices for Management of the Second Stage of Labor. J Midwifery Women Health. 2014; 59, 264-276.
4. Lowdermilk D, Perry S, Cashion K, Alden K. Maternity Women's \& Health Care (11ed), nursing care of the family during labor and birth, ch.(19). United States of America, Elseiver. 2016; p.450, 386.

5. Knapp GS. Implementing AWHONN's Evidence Based Guidelines for Managing the Second Stage of Labor. 2017; 50.

6. Association of Women's Health, Obstetric, \& Neonatal Nursing. Nursing care and management of the second stage of labor (2nd ed). Washington, DC: AWHONN. 2014.

7. Jose A, Mathias A. Effectiveness of Semi-Fowler's Position on Maternal Parameters and Fetal Heart Rate in Primigravid Women during Second Stage of Labour.-. International Journal of Health Sciences and Research (IJHSR). 2015;5(7):283-9.

8. Gupta J K, Hofmeyr G J, \& Shehmar M. "Position in the second stage of labour for women without epidural anaesthesia," The Cochrane Database of Systematic Reviews, 2017; vol. 5 .

9. Association of Women's Health, Obstetric, \& Neonatal Nursing. Nursing care and management of the second stage of labor (2nd ed). Washington, DC: AWHONN. 2016.

10. Ministry of Health and Population MOHP(2015):Egypt Demographic and Health Survey 2014.retrived from.https://dhsprogram.com/pubs/p df/FR302/.pdf.on 2016.

11. Lundeberg T, Lund I, Dahlin L, Borg E, Gustafsson C, Sandin L, Rosén A, Kowalski J, Eriksson SV. Reliability and responsiveness of three different pain assessments. Journal of rehabilitation medicine. 2001 Nov 1;33(6):279-83. 
12. Pillitteri A. Maternal \& child health nursing care of the childbearing and childrearing family. 7 th edn. Chapter 14 prepaing a family for childbirth and parenting. China, Wolters kluwer Health, Lippincott Williams \& Wilkins Co. 2014; pp. 331- 350.

13. Mohamed, S., Nour, S., Elshahat, A., AbdAllah, I. Comparing the Effect of Maternal Semi-Sitting and Dorsal Recumbent versus Lithotomy Positions on the Progress of the Second Stage of Labor and on Labor Outcome. Faculty of Nursing, Ismailia Suez Canal University. The Zagazig Journal. July 2012; volume 8, Num., 2.

14. Thies-Lagergren L, Hildingsson I, Christensson K, Kvist LJ. Who decides the position for birth? A follow-up study of a randomised controlled trial. Women and birth. 2013 Dec 1;26(4):e99-104.

15. Jakeman AR. Maternal Positioning in the Second Stage of Labor and Incidence of Spontaneous Perineal Trauma: A Systematic Review with Meta-Analysis of Randomized Controlled Trials. 2016.

16. Bomfim- Hyppólito S. Influence of the position of the mother at delivery over some maternal and neonatal outcomes. International Journal of Gynecology \& Obstetrics. 1998 Dec 1;63(S1).
17. Thilagavathy G. Maternal birthing position and outcome of labor. The Journal of Family Welfare. 2012; 58(1).

18. Gupta JK, Hofmeyr GJ, Shehmar M. Position in the second stage of labour for women without epidural anaesthesia. The Cochrane Library. 2012 May.

19. Nilsen E, Sabatino H, Lopes MH. The pain and behavior of women during labor and the different positions for childbirth. Revista da Escola de Enfermagem da USP. 2011 Jun;45(3):557-65.

20. Valiani M, Rezaie M, Shahshahan Z. Comparative study on the influence of three delivery positions on pain intensity during the second stage of labor. Iranian journal of nursing and midwifery research. 2016 Jul;21(4):372.

21. Desseauve D, Fradet $\mathbf{L}$, Lacouture $\mathbf{P}$, Pierre F. "Birth is like a marathon" revisiting childbirth by using sport biomechanics approaches. Inisbs-conference proceedings archive 2016 may 5 (vol. 33, no. 1)

22. AlkaDani, V. R. Badhwar, Ganpat Sawant, S., Salian, C. Comparative study of squatting position vs dorsal recumbent position during second stage of labour. Journal of Evidence Based Medicine and Healthcare. 2015 Jan 1;2(54):8769-73. 